\title{
MEDIATISASI JASA LAYANAN MAKANAN MELALUI APLIKASI GOFOOD DAN GRABFOOD
}

\author{
Diyah Ayu Karunianingsih \\ Sekolah Tinggi Multi Media \\ Jl. Magelang, Km. 6, Kutu Patran, Sinduadi, Kec. Mlati, Kabupaten Sleman \\ Daerah Istimewa Yogyakarta, 55284, Indonesia \\ No. Telp./HP: 081290890875 \\ E-mail: ayudiyah@mmtc.ac.id
}

Naskah diterima tanggal 6 Desember 2019, direvisi tanggal 29 Juni 2020, disetujui tanggal 19 Agustus 2020.

\section{MEDIATIZATION OF FOOD SERVICES THROUGH GOFOOD AND GRABFOOD APPLICATIONS}

\begin{abstract}
Abstrak. Teknologi bukan sekedar menjadi media komunikasi dan interaksi namun mampu mengubah perilaku sosial dan budaya dalam hal ini cara hidup masyarakat (way of life). Penelitian ini dilakukan untuk memahami fenomena perubahan perilaku sosial dan budaya (way of life) dengan adanya jasa layanan GoFood dan GrabFood serta alat pembayarannya. Penelitian dilakukan dengan pendekatan teori mediatisasi seperti yang disampaikan Hjarvard. Metode penelitian menggunakan pendekatan fenomenologi, dengan teknik pengumpulan data berupa observasi dan wawancara kepada sepuluh pengguna aplikasi yang cukup intens menggunakan GoFood dan GrabFood sehingga dianggap sudah mewakili untuk memahami perubahan fenomena tersebut. Peneliti juga melakukan observasi partisipan untuk mengecek validitas data. Hasil penelitian diketahui bahwa terjadi perubahan perilaku, sosial, dan budaya (way of life) masyarakat dengan adanya GoFood dan GrabFood, yaitu: (1) perubahan relasi sosial masyarakat; (2) perubahan cara berkomunikasi dan berinteraksi masyarakat; (3) perubahan budaya transaksi pembayaran; (4) perubahan perilaku oleh aktor lain karena beradaptasi dengan sistem aplikasi GoFood/GrabFood; (5) perubahan masyarakat jenis baru. Dari penelitian tersebut juga diketahui bahwa melalui layanan GoFood/GrabFood dan alat pembayarannya Gopay/OVO, mampu menjadi institusi independen yang dengan logikanya sendiri mampu mendistribusikan sumber materi dan simbolik dengan berbagai menu makanan dalam bentuk gambar dan berbagai jenis voucer dan promo, membuat aturan formal dan nonformal yang mampu memaksa institusi lain untuk mengakomodasinya, dan media secara simultan menjadi bagian yang terintegrasi dengan institusi lain dalam hal ini sektor ekonomi.
\end{abstract}

Kata kunci: mediatisasi, logika media, globalisasi, e-commerce.

Abstract. Technology is not merely a medium of communication and interaction, but it might change social and cultural behavior, in this case, people's way of life. This research was conducted to understand the phenomenon of changes in social and cultural behavior through the presence of GoFood and GrabFood services and their payment instruments. This study used the mediatization theory approach, as presented by Hjarvard. The research used a phenomenological approach, with data collection techniques in the form of observations and interviews with ten intense application users using GoFood and GrabFood that are considered enough to represent the population in understanding the changing phenomena. The researcher also conducted participants observation to check data validity. The results showed that there were changes in the behavior, social and culture (way of life) of the community with the existence of GoFood and GrabFood, as follows: (1) changes in social relations; (2) changes in the way people communicate and interact; (3) changes in payment transaction culture; (4) changes in behavior by other actors because of adapting to the GoFood/GrabFood application system; (5) changes in new types of 
society. This research found that GoFood/GrabFood services and its payment instruments Gopay/OVO is able to become an independent institution that by its logic can distribute material and symbolic sources with various menus in the form of images and various types of vouchers and promos, making formal and non-formal rules which can force other institutions to accommodate $i t$, and the media simultaneously become an integrated part with other institutions, in this case, the economic sector.

Keywords: mediatization, media logic, globalization, e-commerce.

\section{PENDAHULUAN}

Modernitas merupakan sebuah tatanan pascatradisional yang ditandai dengan perubahan, selanjutnya ditandai adanya inovasi dan dinamisme. Giddens menjelaskan bahwa institusi modernitas terdiri dari industrialisme, pengawasan, kapitalisme, dan kekuatan militer (Barker, 2011). Dinamika modernitas kapitalis bukan hanya menghasilkan batu bara, kereta, atau tenaga nuklir tetapi juga internet, termasuk smartphone. Revolusi Industri 4.0 saat ini merupakan wujud modernitas yang penuh dengan inovasi dan dinamisme. Menurut Mumtaha \& Khoiri (2019) revolusi industri 4.0 telah menghadirkan berbagai ragam perkembangan teknologi untuk mempermudah segala kegiatan (Mumtaha \& Khoiri, 2019).

Kemajuan teknologi di era revolusi industri 4.0 kian pesat, termasuk teknologi komunikasi dan e-commerce. Bukan hanya untuk berbelanja, platform e-commerce yang menyuguhkan jasa servis di dunia transportasi online mulai bermunculan, seperti Travis Kalanick dan Garret Camp yang merupakan pelopor hadirnya layanan aplikasi transportasi online dengan layanan UberCab yang lahir di San Francisco pada tahun 2010 (Kurnianti, 2017). Aplikasi ini menginspirasi munculnya aplikasi-aplikasi serupa dan memberi pilihan baru bagi pengguna transportasi umum di seluruh belahan dunia dengan memanfaatkan teknologi.

Platform e-commerce fenomenal yang menyuguhkan jasa servis di Indonesia yaitu Gojek dan Grab. Awalnya, pada tahun 2010 Gojek merupakan aplikasi layanan servis panggilan untuk naik motor, berkembang menjadi ojek online baik motor maupun mobil (taksi online). Founder dan CEO Gojek, Nadiem Makarim, seorang social enterpreneurship berinovasi untuk mendorong perubahan sektor transportasi informal agar dapat beroperasi secara profesional dengan mengembangkan layanan aplikasi Gojek. Gojek merupakan perusahaan berjiwa sosial yang memimpin revolusi industri transportasi darat yaitu ojek (Gojek, 2019).

Persaingan e-commerce jasa servis terus berlanjut. Gojek memperluas usahanya pada bisnis pengantaran makanan dengan membuat layanan GoFood yang diluncurkan pada 1 April 2015 (Nugrahanto, 2015). Memasuki tahun 2016, dikutip dari Aziah \& Adawia (2018), sadar jika metode pembayaran seringkali menghambat para pengguna dalam menggunakan layanan-layanan mereka, Gojek meluncurkan metode pembayaran GoPay (Aziah \& Adawia, 2018). Saldo GoPay dapat diisi melalui berbagai cara, mulai dari transfer bank, mobile banking, hingga memberikan uang tunai langsung kepada pengemudi Gojek. Sejak saat itu aplikasi ini berkembang pesat menjadi aplikasi super, sebuah platform multilayanan dengan lebih dari 20 layanan saat ini. Kini Gojek menjadi grup platform teknologi karya anak bangsa terdepan yang melayani jutaan pengguna di Asia Tenggara (Gojek, 2019).

Selain Gojek, aplikasi sejenis yang menjadi rivalnya di Indonesia adalah Grab. Grab merupakan perusahaan teknologi seluler terbesar di Asia Tenggara yang berdiri tahun 2012 di Malaysia. Grab merupakan perusahaan yang menghubungkan jutaan konsumen dengan jutaan pengemudi, pedagang, dan bisnis. Grab memiliki visi "We drive Southeast Asia forward, by elevating the quality of life for everyone" dan slogan "Empowering Southeast Asia Through Technology" (Grab, 2020). Grab tidak mau kalah dengan Gojek, pada tanggal 2 Mei 2016 Grab meluncurkan Grabfood (Grab, 2016). 
Dikutip dari Chan, Maharani \& Tresna (2017) per Januari 2017 aplikasi Gojek sudah diunduh hampir 10 juta kali di Google Play Store, selain itu tersedia pula di App Store (iOS). Sementara aplikasi Grab diunduh hampir 10 juta kali lewat smartphone Android. Dengan teknologi, Gojek maupun Grab mampu menawarkan berbagai kemudahan sebagai solusi masalah sehari-hari masyarakat (Chan, Maharani \& Tresna, 2017). Seperti dikutip dari Anindhita, Arisanty \& Rahmawati (2016), bahwa teknologi aplikasi Gojek mampu mengubah kebiasaan masyarakat yang awalnya mencari ojek/transportasi darat secara manual berubah menjadi secara online melalui aplikasi (Anindhita, Arisanty \& Rahmawati, 2016). Kehidupan sehari-hari telah termediasi oleh aplikasi Gojek atau Grab. Kebiasaan pemanfaatan aplikasi Gojek atau Grab mampu mengubah perilaku manusia dan kemudian mengubah perilaku sosial dan budaya, budaya dalam hal ini adalah way of life atau cara hidup masyarakat. Williams mendefinisikan konsep budaya menggunakan pendekatan universal, yaitu konsep budaya yang mengacu pada makna-makna bersama. Makna ini terpusat pada makna sehari-hari mencakup nilai, benda-benda material/simbolis, dan norma. Kebudayaan adalah pengalaman dalam hidup sehari-hari yaitu berbagai teks, praktik, dan makna semua orang dalam menjalani hidup mereka (Barker, 2011). Kebudayaan yang didefinisikan oleh Williams lebih dekat 'budaya' sebagai keseluruhan cara hidup.

Banyaknya masyarakat yang mengunduh aplikasi Gojek dan Grab tersebut menjadi latar belakang penulis untuk menganalisis salah satu layanan Gojek/Grab. Fokus penelitian bukan perubahan kebiasaan masyarakat dalam mencari ojek/transportasi secara online, namun fenomena layanan jasa beli dan antar makanan yang ditawarkan yaitu layanan GoFood untuk aplikasi Gojek dan layanan GrabFood untuk aplikasi Grab, yang kini digemari oleh masyarakat karena menawarkan kemudahan bagi masyarakat untuk memperoleh makanan. Penelitian ini bertujuan untuk memahami fenomena perubahan sosial dan budaya (way of life) dalam hal ini cara konsumsi/memperoleh makanan yang dilakukan oleh masyarakat pengguna GoFood dan GrabFood dengan adanya teknologi layanan GoFood dan GrabFood serta moda pembayarannya.

\section{LANDASAN KONSEP}

Dalam masyarakat dengan modernitas tinggi (high modernity), media tidak hanya sebatas melakukan peran mediasi namun lebih pada mediatisasi. Mediasi dan mediatisasi memiliki pengertian yang berbeda. Memahami perbedaan antara mediasi dan mediatisasi, perlu memperhatikan sisi fungsi media. Mediasi menitikberatkan pada bagaimana interaksi dan komunikasi terjadi melalui media tersebut, jadi sifatnya lebih netral, artinya media hanya sebagai sarana interaksi dan komunikasi. Sedangkan mediatisasi menurut Altheide \& Snow dalam Hjarvard (2013) berkaitan dengan pengaruh media kepada khalayak, bagaimana khalayak menjadi sangat bergantung pada media (Hjarvard, 2013). Artinya keberadaan media memiliki pengaruh bahkan sampai pada titik ketergantungan masyarakat terhadap media tersebut.

Hjarvard (2013) menjelaskan mediatisasi sebagai berikut: "Mediatization is a social process whereby the society is saturated and inundated by the media to extend that the media cannot longer be thought of separated from other institutions within the society". Konsep mediatisasi menurut Hjarvard (2013) mencakup dua hal, yaitu: (1) Media merupakan institusi independen; (2) Media secara simultan menjadi bagian yang terintegrasi pada institusi lain seperti politik, pekerjaan, keluarga, agama, dan lebih lagi dalam aktivitas yang muncul dalam interaksi keduanya dan media massa. Hjarvard menyebutkan bahwa mediatisasi bermain dengan menggunakan logika media (media logic): "The logic of the media influences the form communication takes, such as how politics is described in media text (Altheide \& Snow, 1979); media logic also influences nature and function of social relations as the sender, the content, and the receivers of the communications" (Hjarvard, 2013).

Esser menjelaskan bahwa penghubung paling penting dalam logika media adalah profesionalisasi dan komersialisasi, diikuti oleh perubahan teknologi (Esser, 2013). Dari 
penjelasan ini maka dapat dipahami bahwa logika media dapat digunakan untuk menafsirkan fenomena sosial budaya di masyarakat yang berkembang akibat perkembangan teknologi. Selanjutnya, yang dimaksud dengan logika adalah modus operasi institusional dan teknologikal media termasuk di dalamnya cara media mendistribusikan sumber material dan simbolik dan menggunakan aturan formal dan non formal (Hjarvard, 2013).

Friederich Krotz dalam Hjarvard (2013) menjelaskan mediatisasi sebagai sebuah proses ketika media mengubah relasi manusia dan perilaku, dan kemudian mengubah sosial dan budaya (Hjarvard, 2013). Budaya yang dimaksud dalam fokus penelitian ini adalah budaya sebagai way of live atau cara hidup manusia khususnya dalam memperoleh makanan. Oleh karena itu pertanyaanpertanyaan terkait media dan komunikasi tidak hanya dibatasi oleh kajian mediasi, seperti pengaruh atau media coverage saja, akan tetapi justru fokus pada mediatisasi yang lebih fundamental.

Secara umum dalam Hepp, Hjarvard, \& Lundby yang dikutip dari Swastika (2018), mediatisasi berusaha menangkap interrelasi antara perubahan di media dengan perubahan sosial kultural. Media selalu berelasi dengan praktik-praktik komunikasi dalam dinamika sosial kultural masyarakat. Dalam lingkup masyarakat modern, media menjadi bagian dari pengartikulasian beragam bidang, seperti politik, ekonomi, edukasi, dan sebagainya. Selain itu, dengan determinasi teknologi yang dimiliki media, maka media akan menjadi faktor kunci yang membawa masyarakat pada jenis masyarakat baru (Swastika, 2018). Sesuai dengan apa yang dikatakan McLuhan (2002) tentang "Medium is the Message", bahwa teknologi merestrukturisasi kehidupan baik privat maupun publik (McLuhan, 2002).

Winfried Schulz \& Krotz dalam Hjarvard (2013) mengidentifikasi empat macam proses ketika media mengubah komunikasi dan interaksi masyarakat, yaitu: (1) Media memperluas kemampuan komunikasi manusia baik waktu dan ruang; (2) Substitusi aktivitas sosial oleh media yang sebelumnya membutuhkan tempat untuk tatap muka (face to face); (3) Media menghasut percampuran (amalgamasi) aktivitas komunikasi tatap muka kombinasi dengan komunikasi yang termediasi, media menginfiltrasi (merembes) dalam kehidupan sehari-hari; (4) Aktor pada sektor yang berbeda harus mengadaptasikan perilaku mereka untuk mengakomodasi penilaian media, format, dan kebiasaan (Hjarvard, 2013).

Thompson dalam Hjarvard (2013) melihat koneksi yang kuat antara mediatization dan konsekuensi mediatisasi terhadap budaya dan munculnya organisasi media yang lebih luas dalam tingkat nasional dan global. Produksi dan distribusi produk simbolik oleh perusahaan mengubah pergerakan komunikasi di masyarakat, antarinstitusi, dan antara institusi dengan individu (Hjarvard, 2013).

Kemampuan media untuk memperluas komunikasi manusia erat kaitannya dengan globalisasi. Dampak globalisasi yang luas cakupannya dalam Ibrahim dan Akhmad yang dikutip Rachmawati (2017), dalam penetrasi dan kecepatannya yang instan mampu merestrukturisasi cara hidup manusia secara mendalam. Dampak yang ditimbulkannya bersifat mendua, atau sering dikenal dengan istilah "global paradox", memberi peluang dan hambatan, positif dan negatif (Rachmawati, 2017). Relasi globalisasi dengan mediatisasi menurut Hjarvard (2013) mencakup dua hal, yaitu: (1) Globalisasi menganggap eksistensi teknik bermakna memperluas komunikasi dan interaksi jarak jauh; (2) Globalisasi menggerakkan proses mediatisasi dengan melembagakan komunikasi dan interaksi yang termediasi dalam banyak konteks baru (Hjarvard, 2013).

\section{METODE PENELITIAN}

Penelitian ini berusaha memahami fenomena perubahan perilaku, sosial, dan budaya dalam arti cara hidup masyarakat dengan adanya layanan GoFood dan GrabFood. Oleh karena itu metode yang digunakan dalam penelitian ini adalah metode penelitian fenomenologi. Wacana fenomenologi harus bisa memberikan deskripsi setepat mungkin tentang apa yang 
hadir dan ada di hadapan kesadaran. Fenomena bagi Husserl dikutip dari Madjid (2014) adalah realitas yang sesungguhnya dengan semboyan "zuruck zu den sachen selbst", objek dalam fenomena adalah objek yang sesuai dengan pemahaman subjek. Kesadaran bukanlah sesuatu yang imanen tetapi bersifat intensional karena selalu merupakan "kesadaran akan sesuatu", jadi bukan kesadaran tanpa arah tujuan.

Penelitian ini merupakan penelitian kualitatif dengan teknik pengumpulan data berupa observasi dan wawancara. Selanjutnya, untuk memperdalam data, juga dilakukan wawancara kepada beberapa orang pengguna layanan GoFood, GoPay, GrabFood, dan OVO. Dalam penelitian ini, peneliti berusaha memahami fenomena perubahan perilaku, sosial, dan budaya dalam hal ini adalah way of life untuk mendapatkan makanan yang terjadi akibat teknologi. Oleh karena itu pihak yang diwawancara adalah pengguna yang cukup intens menggunakan aplikasi layanan GoFood, GoPay, GrabFood, dan OVO yang berdomisili di Yogyakarta yaitu sebanyak 10 orang dan dianggap sudah dapat mewakili untuk memahami fenomena perubahan yang terjadi di masyarakat.

Dalam penelitian ini peneliti menggunakan metode wawancara dan observasi. Peneliti menggunakan informan yang berbeda untuk mengecek kebenaran informasi tersebut. Oleh karena itu informan yang diwawancarai sebanyak 10 orang untuk membandingkan dan mengecek kebenaran informasi. Selain melalui wawancara dan observasi, peneliti juga menggunakan observasi terlibat (participant observation), bertindak sebagai pengguna layanan GoFood/GrabFood dan Gopay/OVO. Observasi partisipan dilakukan terhadap aplikasi Gojek dan Grab, khususnya GoFood, GoPay, GrabFood, dan OVO dengan mengunduh aplikasi Gojek/Grab dan melakukan transaksi GoFood/GrabFood menggunakan Gopay dan OVO, untuk mengecek kebenaran data dari hasil wawancara dan memahami proses transaksi pemesanan makanan serta mengetahui jenisjenis voucer/promo yang ditawarkan Gojek/Grab untuk layanan pembelian makanan.

\section{HASIL PENELITIAN DAN PEMBAHASAN}

Keuntungan yang didapatkan oleh para pengguna layanan GoFood/GrabFood yaitu praktis, mudah dalam pemesanan, tidak perlu keluar rumah, banyak pilihan menu makanan dari berbagai tenant/merchant, ada diskon, ongkos kirim murah, hemat ongkos perjalanan, dan lebih hemat waktu sehingga dapat mengerjakan pekerjaan lain. Seperti yang diungkapkan Desi, pengguna layanan GoFood dan GrabFood yang sering menggunakan GoFood/GrabFood untuk memesan makan siang: "banyak keuntungan saya memesan makanan pake GoFood/GrabFood karena lebih praktis, ada banyak pilihan makanan yang bisa dipesan, dan sering ada diskon juga" (Desi Agustina, pengguna layanan GoFood/GrabFood). Hal yang sama juga disampaikan oleh Arum bahwa dengan fasilitas pesan GoFood/GrabFood menjadi hemat waktu: "Saya merasa sangat terbantu, karena lebih hemat waktu dan hemat ongkos ke rumah makan" (Arum Marwati, pengguna layanan GoFood/GrabFood). Hastuti, salah satu pengguna layanan Gojek/Grab merasa sangat terbantu dengan adanya layanan Gofood/GrabFood: "Jelas sangat terbantu karena lebih praktis banyak pilihan menu makanan tinggal pesan langsung datang". (Hastuti, pengguna layanan GoFood/GrabFood).

\section{Layanan}

GoFood/GrabFood memungkinkan bagi pengguna memesankan makanan untuk orang lain dengan lokasi antar yang berbeda. Artinya pengguna GoFood/GrabFood dapat dengan mudah memesan makanan untuk orang lain yang berada di tempat lain. Seperti pengalaman Ratri Nugrahini, seorang Ibu pekerja kantor yang memesan GoFood untuk orang lain: "Aku di kantor, aku mesenin makan siang buat anak-anak di rumah, pembayaran pake Gopay. Aku info ke Ibuku kalo sekitar sekian menit lagi ada Gofood datang, dan ini sangat membantu" (Ratri Nugrahini, pengguna layanan GoFood/GrabFood).

Dengan keuntungan dan kemudahan memperoleh makanan tersebut, dari hasil wawancara yang dilakukan peneliti, pengguna 
GoFood/GrabFood biasanya memanfaatkan pemesanan makanan menggunakan layanan GoFood dan GrabFood pada saat mereka sedang tidak ingin keluar rumah, pada jam makan siang di kantor (saat jam kerja), pada situasi sedang sibuk baik di rumah maupun di kantor, saat sedang lelah, atau pada malam hari untuk makan malam.

Hal lain yang menarik dari teknologi yang ditawarkan Gojek dan Grab adalah fasilitas pembayaran GoFood/GrabFood dapat dilakukan dengan dua cara, yaitu pembayaran secara tunai dan pembayaran menggunakan e-money. Pembayaran secara tunai adalah pembayaran tunai/cash dengan uang fisik. Secara teknis, pembayaran tunai dilakukan oleh pembeli (pengguna aplikasi) bukan kepada penjual makanan, namun dibayar kepada pengemudi Gojek. Pembayaran jenis kedua yaitu menggunakan e-money, Gopay untuk Gojek dan OVO untuk Grab. GoPay adalah uang virtual berupa saldo uang yang tersimpan dalam aplikasi Gojek, sementara untuk aplikasi Grab disebut OVO. Dengan GoPay/OVO maka proses pembayaran untuk mendapatkan/transaksi makanan menjadi lebih praktis, karena saldo akan terpotong sendiri sesuai jumlah pembayaran dalam aplikasi. Pembeli tidak perlu mencari uang receh untuk membayar dengan uang pas, begitu pula pengemudi Gojek tidak perlu repot mencari uang pas untuk kembalian.

Dua jenis pembayaran baik secara tunai maupun menggunakan e-money memberi pilihan kemudahan untuk pembayaran makanan bagi pengguna. Bagi pengguna yang tidak mengaktifkan e-money maka tetap dapat menggunakan layanan GoFood/GrabFood termasuk bagi pengguna yang sedang kehabisan saldo e-money. Selain itu pengguna yang merasa lebih nyaman membayar secara tunai sesuai kebutuhan tetap dapat dilakukan. Tawaran kemudahan transaksi menggunakan e-money juga menjadi daya tarik bagi pengguna Gojek/Grab untuk bertransakasi pada layanan GoFood/GrabFood. Peneliti melakukan wawancara kepada sepuluh informan untuk mengetahui persepsi dan pandangan mereka terhadap layanan GoFood/GrabFood dan alat pembayarannya. Hal ini untuk mengetahui apakah mereka memiliki persepsi yang sama atau berbeda terhadap hadirnya e-money tersebut.

Dari sepuluh pengguna yang diwawancarai, sebanyak sembilan orang mengaktifkan GoPay dan OVO, sementara itu ada satu orang yang hanya mengaktifkan GoPay namun tidak mengaktifkan $O V O$, dan lebih menyukai pembayaran tunai. Rita, pengguna Gojek/Grab yang lebih memilih membayar secara tunai untuk bertransaksi GoFood: "Saya lebih memilih menggunakan tunai, karena pakai gopay atau ovo biasanya ada minimum belanja untuk mendapatkan diskon" (Rita Widyaningsih, pengguna layanan GoFood/GrabFood). Dari sepuluh orang pengguna tersebut, sebanyak sembilan orang aktif dan lebih menyukai bertransaksi menggunakan e-money. Menurut mereka transaksi menggunakan e-money Gopay/OVO memiliki banyak keuntungan, yaitu cashless (tanpa uang tunai), lebih praktis, mudah memberi tips kepada pengemudi Gojek/Grab, tidak merepotkan pengemudi Gojek/Grab untuk memberi kembalian uang. Seperti yang disampaikan Desi Agustina: "Memilih Gopay untuk pembayaran GoFood karena cashless, gak merepotkan driver utk kasih kembalian, banyak promonya". Santi Endah juga mengatakan hal yang sama: "Gopay dan $O V O$ banyak keuntungan, memudahkan cara pembayaran, dapat diskon, ada cashback, mudah membeli dan memesan dari merchant yang banyak dan beragam". Tidak hanya itu keuntungan yang dirasakan oleh pengguna layanan ini adalah dapat potongan harga dan lebih murah dari pada pembayaran tunai. Sembilan informan mengatakan bahwa dengan transaksi menggunakan Gopay/OVO sering mendapat diskon. Imam Muslimin salah satu pengguna menyebut bahwa dirinya lebih memilih menggunakan e-money dan promo mendorong penggunaan e-money: "Memilih Gopay dan OVO untuk transaksi GoFood dan GrabFood... memang promo itu mendorong penggunaan Gopay dan OVO". Desi salah satu pengguna yang bahkan selalu memanfaatkan promo, salah satunya promo payday yang ditawarkan Gojek/Grab: "Sering. Setiap kali ada promo payday saya ambil".

Promo mampu menarik pengguna Gojek dan Grab untuk menggunakan layanan GoFood dan GrabFood, oleh karena itu 
peneliti mengecek model promo dan besaran promo yang ditawarkan Gojek/Grab dalam layanan Gofood/GrabFood serta mengetahui pembayaran menggunakan e-money sehingga mampu menarik dan mendorong penggunaan Gopay dan OVO. Peneliti melakukan triangulasi sumber data dengan melakukan observasi partisipan sebagai pengguna layanan GoFood/GrabFood dan e-money Gopay dan $O V O$. Observasi partisipan dilakukan dengan membeli makanan melalui GoFood/GrabFood dan membeli makanan di tenant/merchant menggunakan Gopay/OVO di beberapa foodcourt dan restoran yang bekerja sama dengan Gojek/Grab. Penjelasan promo yang ditawarkan Gojek dan Grab akan dijelaskan masing-masing.

Beberapa promo yang ditawarkan Gojek untuk layanan pesanan Gofood (per Desember 2019) ada empat jenis yaitu:

\section{Voucer GoFood, Potongan Harga untuk Transaksi GoFood}

Voucer GoFood digunakan ketika pengguna aplikasi memesan makanan menggunakan layanan GoFood. Voucer berupa potongan langsung saat transaksi dilakukan berupa potongan nominal rupiah dengan besaran tertentu misalnya voucer GoFood potongan sepuluh ribu rupiah dengan masa berlaku tertentu (syarat dan ketentuan berlaku). Voucer GoFood ini biasanya berlaku untuk pembayaran menggunakan GoPay dan voucer diskon akan muncul dan memotong langsung saat transaksi pada aplikasi.

\section{Voucer Gratis Ongkos Kirim untuk Pembelian GoFood}

Voucer gratis ongkos kirim menawarkan potongan ongkos kirim untuk pembelian makanan dengan layanan GoFood. Voucer potongan bisa dalam bentuk free ongkir (bebas ongkos kirim) dengan batasan tertentu sesuai ketentuan, misalnya diskon ongkos kirim sebesar dua puluh lima persen.

\section{Mission}

Mission adalah salah satu komodifikasi voucer GoFood sebagai "iming-iming" atau daya tarik untuk memikat pengguna aplikasi agar terus bertransaksi GoFood sesuai misi yang ditentukan pada aplikasi Gojek. Model misi yang ditawarkan misalnya misi menyelesaikan transaksi GoFood sebanyak empat kali untuk mendapatkan rewards berupa voucer GoFood sebesar sembilan puluh ribu rupiah yang terbagi dalam sembilan voucer masing-masing sepuluh ribu rupiah untuk transaksi selanjutnya. Peneliti melakukan observasi partisipan dengan mengambil Mission ini dan telah selesai melakukan misi. Hasil observasi diketahui bahwa Mission ini akan membuat pengguna terus melakukan pembelian GoFood menggunakan Gopay agar mendapatkan voucer dan terus melakukan top up Gopay untuk dapat menggunakan voucer tersebut untuk pembelian GoFood. Hal ini merupakan bentuk komersialisasi simbolsimbol voucer GoFood yang diperoleh dengan melakukan misi yaitu transaksi pembelian Gofood dikemas secara profesional dalam sebuah sistem aplikasi.

\section{Tebus Murah Voucer GoFood}

Komodifikasi untuk mendapatkan promo voucer GoFood berupa tebus murah voucer GoFood. Untuk mendapatkan voucer GoFood, pengguna aplikasi Gojek dapat membeli voucer dengan harga jauh lebih murah, misal voucer GoFood dengan nominal Tiga Ratus Ribu Rupiah, hanya ditebus menggunakan GoPay dengan harga Dua Puluh Lima Ribu Rupiah. Voucer Tiga Ratus Ribu Rupiah dibagi dalam voucer Sepuluh Ribu Rupiah sebanyak 30 voucer, sehingga total nominal voucer sebesar Tiga Ratus Ribu Rupiah dengan masa berlaku tertentu. Voucer ini kemudian dikomersialisasi dengan membayar/menebus dengan harga murah untuk kemudian digunakan dalam pembelian GoFood.

\section{Potongan Cashback di Tenant/Merchant}

Voucer berupa potongan langsung saat transaksi membeli makanan menggunakan $e$ money GoPay. Potongan cash back ini berupa potongan dalam bentuk persen, misal dua puluh persen, tiga puluh persen, atau empat puluh persen dari harga beli makanan/transaksi. Potongan cash back hanya berlaku pada saat transaksi pembelian langsung di tenant/merchant tertentu berlabel Gojek dan biasanya terdapat keterangan cash back sekian persen di toko tersebut. Jadi bukan 
potongan untuk pembelian menggunakan layanan GoFood. Potongan cash back biasanya ditentukan batas maksimal nominal cash back dalam setiap transaksi, misalnya potongan tiga puluh persen maksimal Dua Puluh Ribu Rupiah dan hanya berlaku satu kali transaksi dalam satu hari, atau berlaku sekali dalam satu akun pengguna. Potongan cash back berbeda dengan voucer GoFood, karena untuk menggunakan voucer cash back GoPay, pembeli harus datang ke tenant/merchant dan bertransaksi melalui barcode di tenant/merchant yang menawarkan promo cash back, artinya tidak semua tenant/merchant pada saat yang sama memberikan promo cash back.

\section{Promo Gopay "Payday"}

Promo cash back "payday" juga menjadi salah satu promo menarik, karena potongan voucer cash back yang diberikan sebesar lima puluh persen. Cash back "payday" ditawarkan pada momentum tertentu dan biasanya berlangsung selama dua hingga tiga hari dan hanya berlaku untuk transaksi langsung di tenant/merchant yang memberikan promo "payday". Promo "payday" ini bekerja sama dengan sejumlah tenant/merchant di berbagai pusat perbelanjaan, restoran, dan foodcourt. Pengguna akan mendapatkan diskon dalam bentuk cash back (uang kembali) yang langsung masuk ke Gopay. Dari observasi yang dilakukan di beberapa foodcourt dan pusat perbelanjaan, promo "payday" ditandai dengan tampilan logo "payday" yang biasanya ditempatkan di bagian depan tenant/merchant sehingga mudah dilihat oleh pengunjung.

Tidak hanya Gojek yang memberikan berbagai jenis promo, Grab juga ingin menarik pengguna aplikasi dengan menawarkan promo untuk GrabFood dan transaksi membeli makanan langsung di tenant/merchant menggunakan e-money OVO Balance. Pengamatan yang dilakukan penulis pada aplikasi Grab, diketahui bahwa komodifikasi e-money OVO berbeda dengan Gojek, e-money OVO Balance terdiri dari OVO Cash, OVO Points dan GrabReward Points. OVO Cash adalah uang virtual yang ada dalam saldo OVO, sedangkan OVO Points adalah saldo virtual juga namun dalam bentuk point, sementara GrabReward Points adalah saldo
$O V O$ dalam bentuk point yang terkumpul dari hasil reward. Reward ini diperoleh dari transaksi menggunakan OVO. Voucer Grab untuk memperoleh makanan yang ditawarkan ada tiga model (per Desember 2019) yaitu:

\section{Voucer GrabFood}

Voucer ini berlaku untuk transaksi GrabFood dengan memasukkan kode voucer misalnya gfyummy, motoranwaeoke, palugada, gfyogyoh, dan grabfood5. Dari observasi partisipan yang dilakukan peneliti dengan menjadi pengguna layanan GrabFood, diketahui bahwa beberapa promo kode voucer ditawarkan dalam menu my rewards (pada masing-masing aplikasi pengguna), namun ada pula kode promo lain yang bisa digunakan oleh semua pengguna bergantung promo tertentu. Pengguna dapat memilih kode voucer yang lebih menguntungkan dan lebih banyak potongan untuk bertransaksi GrabFood. Masing-masing voucer berlaku syarat dan ketentuan. Dengan memasukkan kode voucer, maka akan ada potongan langsung pada saat pembayaran GrabFood. Grab memberikan beberapa potongan kode voucer yang hanya bisa digunakan untuk transaksi GrabFood menggunakan $O V O$ namun beberapa kode voucer bisa digunakan meski pembayaran menggunakan uang tunai.

\section{Promo Cash back dalam Bentuk OVO Point}

Potongan berlaku untuk transaksi di tenant/merchant mitra Grab menggunakan emoney OVO. Model potongan yang ditawarkan dalam bentuk persentase dari harga makanan, dengan ketentuan maksimal nominal misal potongan lima puluh persen dengan maksimal potongan Tiga Puluh Ribu Rupiah, potongan enam puluh persen dengan maksimal potongan Dua Puluh Lima Ribu Rupiah. Promo cashback tidak diberikan dalam bentuk nomial uang yang dikembalikan ke $e$-wallet (OVO cash) namun dalam bentuk poin yang disebut OVO Points. Besaran cashback OVO Points sebesar potongan nominal rupiah, hanya saja dalam bentuk poin. OVO Points juga dapat digunakan untuk transaksi pembayaran sesuai dengan ketentuan yang ditetapkan Grab. Jadi transaksi menggunakan $O V O$ dapat dilakukan dalam 
beberapa jenis yaitu menggunakan $O V O$ Points, OVO Cash atau gabungan OVO Cash dan $O V O$ Points dalam satu transaksi. Peneliti mencoba melakukan pembelian makanan di salah satu restoran di pusat perbelanjaan menggunakan $O V O$ yang sedang ada promo cashback tiga puluh persen. Pada transaksi tersebut peneliti mendapatkan cashback tiga puluh persen dari jumlah transaksi dalam bentuk OVO point sebesar Dua Belas Ribu Lima Ratus Rupiah.

\section{Promo "Payday" Grab dan Promo "Hore Gajian"}

Hasil observasi promo "payday", Grab memberikan potongan 60 persen dengan ketentuan batas maksimal potongan. Selain promo "payday", Grab juga memberikan promo "Hore Gajian" dengan menawarkan promo diskon hingga 60 persen. Berbagai promo diskon, voucer, dan potongan harga dalam bentuk simbol-simbol dalam aplikasi tersebut merupakan wujud komersialisasi voucer untuk membeli makanan, dengan perantara/fasilitas Gojek/Grab. Komersialisasi simbol-simbol ini secara profesional dihubungkan dengan aplikasi GoFood/GrabFood dengan melibatkan banyak pihak seperti tenant/merchant dan penyedia layanan top up e-money yang diatur secara profesional dengan logika media dalam sebuah sistem aplikasi Gojek/Grab. Seperti Esser yang menyebut bahwa penghubung paling penting dalam logika media adalah profesionalisasi dan komersialisasi, diikuti oleh perubahan teknologi. Berbagai jenis promo tersebut menarik pengguna agar terus bertransaksi menggunakan layanan GoFood/GrabFood dan e-money untuk memperoleh makanan. Dengan fasilitas Gopay dan $O V O$ dan berbagai promo diskon dan cash back, maka para pengguna secara rutin mengisi Gopay/OVO untuk kebutuhan transaksi dengan jumlah yang berbeda-beda. Dari 10 orang yang diwawancara, sebanyak sembilan orang sudah rutin mengisi/top up Gopay/OVO. Mayoritas digunakan untuk memesan makanan baik melalui GoFood/GrabFood maupun langsung bertransaksi di. Ada yang top up seminggu sekali atau sebulan sekali.
Dari wawancara yang dilakukan kepada sepuluh pengguna Gojek/Grab rata-rata dalam sebulan mereka melakukan top up e-money untuk Gopay dan $O V O$ dari ratusan ribu hingga jutaan. Seperti Wisynu yang melakukan top up dua kali dalam sebulan: "Top up Gopay jarang sekali, sedang top up OVO minimal dua kali dalam sebulan. Nominal top up gopay Seratus Ribu kalau OVO satu juta" (Muhammad Wisynu, pengguna layanan Gopay/OVO). Wisynu lebih menyukai top up OVO dibanding Gopay, sedangkan Santi lebih menyukai top up Gopay dari pada $O V O$ sehingga besaran top up berbeda, karena lebih sering menggunakan layanan Gojek dari pada Grab: "Sebulan biasanya top up satu kali, Gopay Lima Ratus Ribu Rupiah sedangkan $O V O$ Tiga Ratus Ribu Rupiah" (Santi Endah, pengguna layanan Gopay/OVO).

GoPay/OVO dapat digunakan untuk bertransaksi dalam semua menu layanan Gojek/Grab seperti membayar GoFood, GoCar, Gojek, GoSend dan menu lain dalam aplikasi. Untuk memenuhi moda transaksi $e$ money yang ditawarkan Gopay dan OVO inilah kemudian pihak dari sektor lain akhirnya menyesuaikan untuk menyediakan jasa fasilitas top up Gopay dan OVO. Nominal GoPay/OVO dapat ditambah (top up) melalui beberapa cara di antaranya transfer rekening bank (ATM/m-banking), pembayaran melalui jasa top up seperti Alfamart, atau top up melalui pengemudi Gojek.

\section{Mediatisasi Teknologi dalam Layanan GoFood/GrabFood dan E-Money Memunculkan Masyarakat Jenis Baru}

Sebelumnya, seseorang harus memasak sendiri atau membeli makanan langsung di warung makan/restoran untuk memperoleh makanan. Transaksi membeli makanan terjadi di warung makan/restoran tersebut. Ada aktivitas tatap muka antara pembeli dan penjual. Selain itu ada proses transaksi jual beli antar pembeli dan penjual menggunakan uang cash (tunai) dan ada proses serah terima barang yang dibeli antara penjual dan pembeli makanan.

Dengan adanya teknologi, Gojek dan Grab memberikan moda layanan jual beli makanan yang berbeda. Layanan yang ditawarkan Gojek dan Grab melalui GoFood 
dan GrabFood, beserta alat pembayarannya Gopay dan $O V O$ mampu memberi kemudahan bagi pengguna aplikasi untuk mendapatkan makanan serta mampu mengubah perilaku dan budaya (way of life) masyarakat dalam memperoleh makanan. Dari uraian pada pembahasan sebelumnya maka dapat diketahui adanya perubahan perilaku sosial dan budaya (way of life) pengguna Gofood/GrabFood yaitu:

\section{Perubahan Relasi Sosial Masyarakat}

Teknologi mampu mengubah relasi sosial masyarakat. Dengan layanan GoFood atau GrabFood pembeli tidak bertemu penjual tetapi melalui media perantara yaitu pengemudi Gojek/Grab. Pembeli tidak bertemu dan tidak melakukan transaksi jual beli makanan dengan penjual, namun proses ini dilakukan oleh pengemudi Gojek/Grab. Proses transaksi mengalami perubahan seperti yang dijelaskan pada pembahasan sebelumnya yaitu tidak terjadi pertemuan langsung (face to face) antara pembeli dan penjual seperti proses jual beli pada umumnya sebelum ada layanan GoFood dan GrabFood. Pembeli tidak akan mengetahui, mengenal bahkan kemungkinan mengenal lebih dekat dengan penjual, karena sama sekali tidak terjadi proses pertemuan. Relasi yang muncul adalah antara pembeli dengan pengemudi Gojek/Grab hanya sebatas pesan dan antar makanan, tanpa mengetahui/mengenal lebih dekat pengemudi Gojek/Grab. Relasi antara pembeli dengan penjual berubah dengan adanya perantara teknologi dan pengemudi Gojek/Grab sebagai pihak ketiga yang menjadi mediator. Seperti yang disampaikan Friederich Krotz dalam (Hjarvard, 2013) yang menjelaskan bahwa mediatisasi sebagai sebuah proses dimana media mengubah relasi manusia dan perilaku, dan kemudian mengubah sosial dan budaya.

Determinasi teknologi yang dimiliki media dalam hal ini Gojek/Grab dengan adanya layanan GoFood/GrabFood, maka media akan menjadi faktor kunci yang membawa masyarakat pada jenis masyarakat baru yang termediasi oleh teknologi (Krotz dalam Hjarvard, 2013). Hal ini juga terwujud dari layanan GoFood/GrabFood yang memungkinkan pesanan makanan tidak harus diterima oleh pembeli sendiri, aplikasi ini memungkinkan pengguna aplikasi membeli makanan untuk orang lain dengan penulisan lokasi antar di lokasi yang dituju/diinginkan. Relasi yang terjalin semakin berubah karena pemesan/pembeli dan penerima makanan adalah orang yang berbeda. Pembeli tidak bertemu pengemudi Gojek/Grab dan penjual makanan. Pertemuan hanya antara pengemudi Gojek/Grab dengan penjual dan pengemudi Gojek/Grab dengan orang lain sebagai penerima makanan saat makanan tersebut diantar oleh pengemudi Gojek/Grab.

\section{Perubahan Cara Berkomunikasi dan Berinteraksi Masyarakat}

Layanan GoFood/GrabFood menjadi media yang mengubah komunikasi dan interaksi masyarakat (Winfried Schulz \& Krotz dalam Hjarvard, 2013) yang diidentifikasi dalam empat macam proses, yaitu: (a) Melalui layanan aplikasi tersebut mampu memperluas kemampuan komunikasi manusia baik waktu dan ruang. Dari sisi waktu, sebelum ada GoFood/GrabFood, komunikasi akan terbatas karena tidak ada aplikasi yang memudahkan masyarakat untuk memesan makanan. Seseorang hanya dapat memesan makanan saat toko buka, atau memesan jika memiliki kontak person penjual/toko tersebut. Artinya terbatas dari jumlah penjual dan jam layanan. Namun dengan adanya layanan GoFood/GrabFood, komunikasi untuk pesan makanan melalui aplikasi dapat dilakukan 24 jam selama merchant/tenant buka dan melayani pembelian makanan. Kerjasama Gojek/Grab dengan banyak tenant/merchant membuat pengguna/masyarakat memiliki pilihan tenant/merchant yang dapat melayani pembelian pada pagi hari, siang hari, malam hari bahkan dini hari, karena ada pula tenant/merchant yang buka 24 jam. Sementara dari sisi ruang, komunikasi pesan makanan melalui aplikasi tersebut dapat melayani dalam lingkup ruang yang lebih luas jaraknya. Bukan hanya membeli makanan di tenant/merchant yang jaraknya dekat, namun bisa pula dari jarak yang cukup jauh dalam satu daerah tersebut. Selain itu aplikasi ini juga memungkinkan digunakan di daerah lain, misalnya ketika pengguna sedang berada di luar kota bahkan di negara lain yang menjadi 
area operasi Gojek/Grab. Sebelum ada GoFood/GrabFood, untuk membeli makanan harus datang langsung ke toko makanan baik yang berada pada jarak dekat atau jarak jauh. Biasanya jarak yang terlalu jauh menjadi pertimbangan seseorang untuk membeli makanan sehingga lebih memilih mencari rumah makan yang lebih dekat. Dengan GoFood/GrabFood maka orang tidak perlu jauh-jauh datang ke toko makanan yang diinginkan. Komunikasi pesan dan antar makanan terhubung/terlayani oleh pengemudi Gojek/Grab; (b) Layanan GoFood/GrabFood menjadi substitusi aktivitas sosial yaitu transaksi jual beli antara pembeli dan penjual yang sebelumnya membutuhkan tempat dan ruang untuk tatap muka (face to face) menjadi termediasi oleh aplikasi layanan GoFood/GrabFood; (c) Layanan GoFood/GrabFood mampu menghasut percampuran (amalgamasi) aktivitas komunikasi tatap muka dengan kombinasi komunikasi yang termediasi. Komunikasi transaksi jual beli makanan bukan lagi oleh pembeli dengan menjual namun diwakili oleh pengemudi Gojek/Grab dan aplikasi. Pesanan makanan dari pengguna termediasi oleh aplikasi kemudian proses transaksi terwakili oleh pengemudi Gojek/Grab, selanjutnya makanan diantar oleh pengemudi Gojek/Grab kepada pembeli. Aplikasi Gojek/Grab menginfiltrasi (merembes) dalam kehidupan sehari-hari; dan sebagai akibatnya; (d) Aktor pada sektor yang berbeda harus mengadaptasikan perilaku mereka untuk mengakomodasi penilaian media, format, dan kebiasaan, yaitu menyesuaikan aturan main pada aplikasi Gojek/Grab.

Aplikasi Gojek/Grab melalui layanan yang ditawarkan mampu memperluas komunikasi manusia. Hal ini erat kaitannya dengan globalisasi. Hjarvard (2013) menyebut bahwa relasi globalisasi dengan mediatisasi mencakup dua hal: (1) Globalisasi menganggap eksistensi teknik bermakna memperluas komunikasi dan interaksi jarak jauh. Terbukti pembeli (pengguna layanan Gojek/Grab) dapat memesan makanan (GoFood/GrabFood) dari jarak dekat hingga jarak jauh dari lokasi merchant/tenant; (2) Globalisasi menggerakkan proses mediatisasi dengan melembagakan komunikasi dan interaksi yang termediasi dalam banyak konteks baru, seperti komunikasi dalam proses pembelian makanan (Gofood/GrabFood) yang tidak membutuhkan pertemuan langsung (face to face) antara pembeli dan penjual makanan, namun dimediasi oleh pengemudi Gojek/Grab.

Di sisi lain, teknologi pada aplikasi Gojek dan Grab mampu menjadi organisasi media yang dapat menghubungkan relasi antara Gojek/Grab, pengemudi Gojek/Grab, merchant/tenant, dan pengguna layanan aplikasi Gojek/Grab dalam lingkup yang lebih luas dalam tingkat lokal, nasional, bahkan global. Hal ini terjadi misalnya ketika pengguna Gojek/Grab memesan makanan dari berbagai penjual makanan yang ada pada aplikasi Gojek/Grab di wilayah lokal di daerah tersebut. Namun tidak hanya itu, ketika pengguna sedang berada di kota/daerah lain bahkan luar pulau dalam satu negara di Indonesia yang termasuk area operasi Gojek/Grab maka tetap dapat menggunakan layanan GoFood/GrabFood untuk memesan makanan. Pada saat proses pemesanan kemudian terjadi praktik-praktik komunikasi antara pengguna layanan dengan pengemudi Gojek/Grab yang merupakan orang yang tidak dikenal yang dimediasi oleh aplikasi Gojek/Grab. Hal ini menunjukkan bahwa ada koneksi yang kuat antara mediatisasi GoFood/GrabFood dan konsekuensi mediatisasi terhadap budaya dan munculnya organisasi media yang lebih luas dalam tingkat nasional dan global (Thompson dalam Hjarvard, 2013).

Di sini produksi dan distribusi produk simbolik melalui layanan GoFood/GrabFood mengubah pergerakan komunikasi di masyarakat, antarinstitusi dan antara institusi dengan individu (Thompson dalam Hjarvard, 2013), dalam hal ini antara Gojek/Grab, pengemudi Gojek/Grab, merchant/tenant, dan pengguna layanan Gojek/Grab di lingkup lokal, bahkan nasional.

\section{Budaya Transaksi Pembayaran Menggunakan E-money}

Pembayaran menggunakan e-money yaitu GoPay dan $O V O$ mampu menciptakan budaya (way of life) transaksi baru untuk memperoleh makanan, yaitu: (1) dari yang 
awalnya menggunakan uang tunai kemudian transaksi banyak menggunakan e-money; (2) dengan adanya promo dan voucer untuk pembelian GoFood/GrabFood maupun transaksi di tenant/merchant maka muncul praktik mengecek promo/voucer yang dimiliki/bisa digunakan untuk transaksi. Ada kebiasaan yang berubah, sebelum ada Gopay/OVO dengan segala promo, masyarakat membeli makanan tanpa memikirkan ada promo, karena harga makanan tetap dan tidak ada potongan harga. Namun kemudian berubah kebiasaan mengecek promo sebelum memesan atau menetapkan makanan yang akan dibeli dalam aplikasi GoFood/GrabFood. Tidak hanya mempertimbangkan jenis makanan yang memang ingin dimakan namun terlebih dahulu mengecek, membandingkan, dan mempertimbangkan besaran diskon (cash back) antara promo GoFood dan GrabFood.

Dari wawancara kepada 10 informan, mereka memutuskan memesan GoFood/GrabFood dengan mencari/mempertimbangkan promo karena lebih murah dan hemat. Renita Sukma di antaranya, sebelum memesan makanan seringkali mengecek promo GoFood/GrabFood melihat aplikasi mana yang sedang memberikan promo lebih besar antara Gojek atau Grab. Menimbang antara besaran promo sambil menyesuaikan makanan yang ingin dibeli, jika sudah cocok antara promo dan menu makanan yang diinginkan, baru kemudian memesan GoFood/GrabFood.

Perubahan perilaku mengecek, membandingkan, dan mempertimbangkan besaran promo diskon (cash back) tidak hanya berlaku pada saat pengguna memesan makanan GoFood/GrabFood. Ketika mereka makan di rumah makan, foodcourt atau restoran (tenant/merchant) juga muncul praktik perubahan perilaku yaitu mereka memilih merchant yang bermitra dengan Gojek/Grab dan sedang memberikan promo. Promo biasanya dapat dilihat di bagian depan tenant/merchant terdapat keterangan promo GoPay/OVO, selain itu informasi promo juga ada pada aplikasi Gojek/Grab atau akun instragram@gojekpromo. Perilaku mengecek cash back dilakukan untuk menentukan menu makanan yang akan dibeli dan e-money yang akan digunakan untuk transaksi.

Dari hasil observasi dan wawancara, seringkali pengguna Gopay/OVO memilih menu di tenant tersebut karena sedang promo, bahkan pada saat-saat tertentu memungkinkan pengguna Gopay/OVO berubah pilihan makanan karena promo. Desi Tina mengatakan pernah berubah pilihan karena promo: "Pernah, waktu itu pengen beli minuman di Chatime ternyata ada promo lebih menarik di Koma, jadinya beli minum di Koma”. Hal yang sama juga disampaikan Nur Laili Elisa mengatakan berubah pikiran memilih menu makanan: "Awalnya pengen makan ayam, namun karena ada promo di merchant lain dan itu sepaket dengan minum, dan harganya jatuhnya lebih murah, makanya ganti pilihan. Sebenernya saya tidak suka minuman ocha di paket itu".

\section{Adaptasi Perilaku oleh Aktor lain}

Dengan layanan GoFood/GrabFood dan alat pembayanan Gopay/OVO maka seperti yang disampaikan Winfried Schulz \& Krotz (Hjarvard, 2013) aktor pada sektor yang berbeda harus beradaptasi dengan moda layanan pemesanan makanan dan pembayaran yang ditawarkan Gojek/Grab. Adaptasi ini untuk mengakomodasi penilaian media, format, dan kebiasaan, yaitu menyesuaikan aturan main pada aplikasi Gojek/Grab. Adaptasi yang muncul di antaranya: (1) Tenant/merchant yang memiliki usaha makanan pada akhirnya ikut terjun bekerja sama menjadi mitra Gojek/Grab. Kerjasama tersebut akan memperluas display untuk menawarkan berbagai jenis menu makanan dan segmentasi konsumen menjadi lebih luas yaitu semua pengguna Gojek/Grab secara lokal, nasional, dan global. Display untuk menawarkan menu makanan ini termediasi oleh aplikasi Gojek/Grab; (2) Masing-masing tenant/merchant pada akhirnya menyesuaikan model/proses transaksi mulai dari pesanan, transaksi, pembayaran, dan sebagainya sesuai Standard Operating Procedure (SOP) pada aplikasi Gojek/Grab (GoFood/GrabFood), termasuk menyediakan alat transaksi emoney/e-wallet untuk transaksi menggunakan GoPay/OVO; (3) Untuk memenuhi model transaksi yang dimediasi oleh GoPay dan $\mathrm{OVO}$ 
dan untuk memenuhi permintaan top-up GoPay/OVO, maka aktor pada sektor yang berbeda pada akhirnya juga menyesuaikan, misalnya bank memfasilitasi menu untuk topup GoPay/OVO (melalui transfer ATM dan $m$ banking), convenience stores seperti Alfamart juga menyediakan layanan top-up Gopay/OVO.

\section{Perubahan Masyarakat Jenis Baru}

Perubahan perilaku masyarakat akibat teknologi seperti yang dijelaskan sebelumnya, pada akhirnya mulai bergerak pada masyarakat jenis baru yang termediatisasi teknologi sesuai Hepp, Hjarvard, \& Lundby (Swastika, 2018). Masyarakat ini adalah masyarakat yang melek teknologi pengguna aplikasi e-commerce dan e-money, dan merasa teruntungkan dengan menggunakan fasilitas aplikasi (Gojek/Grab, GoFood/GrabFood, GoPay/OVO). Gambaran masyarakat jenis baru yang memilih kepraktisan untuk mendapatkan makanan dengan layanan beli dan antar makanan (GoFood/GrabFood) oleh pihak ketiga/perantara (pengemudi Gojek/Grab) dengan memanfaatkan teknologi, dan masyarakat yang memiliki kebiasaan lebih selektif dalam memilih promo yang lebih besar untuk membeli makanan dengan mengunduh beberapa jenis aplikasi e-money/e-wallet.

\section{PENUTUP}

\section{Simpulan}

Mediatisasi layanan GoFood/GrabFood dan alat pembayarannya bermain dengan menggunakan logika media (media logic) yang diterapkan Gojek/Grab melalui aplikasinya. Pada akhirnya semua akan bergantung pada media (Gojek/Grab) ketika institusi sosial dan budaya serta moda komunikasi dan interaksi berubah sebagai konsekuensi dari pertumbuhan pengaruh media. Dengan aplikasi Gojek/Grab, masyarakat mulai bergerak mengikuti perubahan dan logika yang diterapkan Gojek/Grab. Dari uraian ini maka dalam proses modernitas yang tinggi dalam konsep mediatisasi, media dalam hal ini Gojek/Grab tidak hanya bersikap netral sebagai sarana komunikasi dan interaksi tapi media mampu mengubah perilaku manusia, sehingga media bukan sekedar melakukan mediasi namun lebih pada mediatisasi. Melalui layanan GoFood/Grab Food dan alat pembayarannya Gopay/OVO, mampu menjadi institusi independen yang dengan logikanya sendiri mampu mendistribusikan sumber materi dan simbolik dengan berbagai menu dalam bentuk gambar dan berbagai jenis voucer dan promo, membuat aturan formal dan nonformal yang mampu memaksa institusi lain untuk mengakomodasinya, dan media secara simultan menjadi bagian yang terintegrasi dengan institusi lain dalam hal ini sektor ekonomi. Pada akhirnya media mengubah relasi manusia dan perilaku kemudian mengubah sosial dan budaya (way of life). Mediatisasi berusaha menangkap interrelasi antara perubahan di media dengan perubahan sosial kultural. Media selalu berelasi dengan praktik-praktik komunikasi dalam dinamika sosial kultural masyarakat. Hal ini sesuai dengan yang disampaikan Hjarvard (2013) bahwa logika media dapat digunakan untuk menafsirkan fenomena sosial budaya yang berkembang di masyarakat akibat perkembangan teknologi.

\section{Saran}

Aplikasi Gojek dan Grab dengan layanan GoFood dan GrabFood mampu membuat perubahan sosial dan budaya (cara hidup) masyarakat. Masyarakat memanfaatkan layanan GoFood dan GrabFood untuk membeli makanan. Hal ini membuka ruang bagi industri makanan untuk bekerja sama sebagai mitra penyedia makanan. Layanan aplikasi ini memungkinkan UMKM dan industri makanan rumahan untuk ikut menjajakan menu makanan di etalase menu pada aplikasi Gofood/GrabFood, bahkan bagi mereka yang tidak memiliki rumah makan/warung secara fisik (bangunan) untuk berjualan. 


\section{DAFTAR PUSTAKA}

Anindhita, W., Arisanty, M. \& Rahmawati, D. (2016) ANALISIS PENERAPAN TEKNOLOGI KOMUNIKASI TEPAT GUNA PADA BISNIS TRANSPORTASI OJEK ONLINE (Studi pada Bisnis Gojek dan Grab Bike dalam Penggunaan Teknologi Komuniasi Tepat Guna untuk Mengembangkan Bisnis Transportasi). In: Prosiding Seminar Nasional Indocompac. [Online]. 2016 Jakarta, Universitas Bakrie. pp. 712-729. Available from: http://journal.bakrie.ac.id/index.php/INDOC OMPAC/article/view/1638.

Aziah, A. \& Adawia, P.R. (2018) Analisis Perkembangan Industri Transportasi Online di Era Inovasi Disruptif(Studi Kasus PT Gojek Indonesia). Cakrawala. [Online] 18 (2), 149-156. Available from: https://ejournal.bsi.ac.id/ejurnal/index.php/c akrawala/article/view/4117.

Barker, C. (2011) Cultural Studies: Teori dan Praktek. Nurhadi (ed.). Bantul, Kreasi Wacana Offset.

Chan, A., Maharani, M. \& Tresna, P.W. (2017) PERBANDINGAN PENGALAMAN PENGGUNA PADA APLIKASI MOBILE GO-JEK DAN GRAB (STUDI PADA KONSUMEN PT GO-JEK DAN PT GRAB INDONESIA DI DKI JAKARTA). AdBispreneur. [Online] 2 (2), 163-173. Available from: doi:10.24198/adbispreneur.v2i2.13183.

Esser, F. (2013) Mediatization as a Challenge: Media Logic Versus Political Logic. In: H Kriesi, Sandra Lavanex, Frank Esser, J Matthes, et al. (eds.). Democracy in the Age of Globalization and Mediatization. [Online]. London, Palgrave Macmillan UK. pp. 155176. Available from: doi:10.1057/9781137299871 7.

Gojek (2019) Tentang Kami | Gojek. [Online]. 2019. Available from: https://www.gojek.com/about/ [Accessed: 18 September 2019].

Grab (2016) Grab Beta Launches Food Delivery
Service, GrabFood, in Jakarta. [Online]. 2016. grab.com. Available from: https://www.grab.com/id/en/press/others/gra b-luncurkan-layanan-pengantaran-makanangrabfood-versi-beta-di-jakarta/ [Accessed: 18 September 2019].

Grab (2020) It started with a question. [Online]. 2020. grab.com. Available from: https://www.grab.com/id/en/brand-story/ [Accessed: 18 September 2019].

Hjarvard, S. (2013) The Mediatization of Culture and Society. [Online]. Routledge. Available from: doi:10.4324/9780203155363.

Kurnianti, A.W. (2017) Komunikasi Pemasaran Transportasi Online NGuberJEK. Jurnal Komunikasi dan Kajian Media. [Online] 1 (1), 69-84. Available from: https://jurnal.untidar.ac.id/index.php/komuni kasi/article/view/392.

McLuhan, M. (2002) The Medium is the Message. In: Kelly Askew \& Richard R. Wilk (eds.). The Anthropology of Media: A Reader. Oxford, Blackwell. p.

Mumtaha, H.A. \& Khoiri, H.A. (2019) Analisis Dampak Perkembangan Revolusi Industri 4.0 dan Society 5.0 Pada Perilaku Masyarakat Ekonomi (E-Commerce). JURNAL PILAR TEKNOLOGI: Jurnal Ilmiah Ilmu Ilmu Teknik. [Online] 4 (2), 55-60. Available from: doi:10.33319/piltek.v4i2.39.

Nugrahanto, P. (2015) GO-JEK Luncurkan Layanan Delivery Makanan GO-FOOD. [Online]. 2015. Techinasia. Available from: https://id.techinasia.com/gofood-gojeklayanan-delivery-makanan.

Rachmawati, F. (2017) Media dan Demokrasi di Era Global: Studi Dakwah Islam Kontemporer di Indonesia. Journal of Islamic Studies and Humanities. [Online] 2 (2), 157173. Available from: https://journal.walisongo.ac.id/index.php/JIS $\mathrm{H} /$ article/view/2521.

Swastika, G.L.D. (2018) Mediatisasi \#stopfoodwaste: Studi Kasus pada Garda Pangan. Jurnal Ilmu Komunikasi AKRAB. [Online] 3, 413-436. Available from: http://ojs.akrb.ac.id/index.php/akrab/article/ view/59/32. 